\title{
Estudo Experimental do Processo de Rotomoldagem de PELBD: Efeitos sobre a Morfologia e Estabilidade Dimensional
}

\author{
Tiago Boni Comisso \\ Pós-graduando do Programa de Pós-graduação em Engenharia e Ciência de Materiais, UEPG \\ Carlos Alberto Silva de Lima \\ Aluno de Iniciação Científica - Engenharia de Materiais, UEPG \\ Benjamim de Melo Carvalho \\ Departamento de Engenharia de Materiais/Programa de Pós-graduação em Engenharia e Ciência de Materiais, UEPG
}

\begin{abstract}
Resumo: No presente estudo o empenamento de peças de polietileno linear de baixa densidade (PELBD) moldadas por rotomoldagem foi investigado. O efeito de diferentes fatores como espessura da peça, taxa de resfriamento e diâmetro de tubo de ventilação foi avaliado. Além dos experimentos de rotomoldagem, uma técnica alternativa denominada "Hot Press" foi também aplicada para investigar o empenamento de dois diferentes PELBD sob condições típicas da rotomoldagem quanto ao resfriamento assimétrico. Cristalinidade e morfologia esferulítica ao longo da espessura das peças rotomoldadas foram avaliadas por Calorimetria Exploratória Diferencial (DSC) e Microscopia Ótica de Luz Polarizada. Verificou-se que o grau de empenamento aumenta com a taxa de resfriamento. O aumento do diâmetro do tubo de ventilação é mais efetivo na redução do empenamento principalmente em menores taxas de resfriamento. Nos experimentos de "Hot Press" o PELBD com menor índice de fluidez e maior módulo de flexão apresentou menor empenamento. Nos experimentos de "Hot Press" a espessura das peças afetou o empenamento somente para maiores taxas de resfriamento. Em geral, a cristalinidade e o tamanho de esferulitos se mostraram menores nas posições ao longo da espessura das peças rotomodadas onde as taxas de resfriamento eram mais rápidas.
\end{abstract}

Palavras-chave: Rotomoldagem, empenamento, polietileno linear de baixa densidade.

\section{Experimental Study of Rotational Molding Process of LLDPE: Effects on Morphology and Dimensional Stability}

Abstract: In the present study the warpage of rotationally molded parts of a linear low density polyethylene (LLDPE) was investigated. The effect from different processing factors such as part thickness, cooling condition and diameter of the venting tube was evaluated. In addition to the rotational molding experiments, an alternative experimental technique, referred to as "Hot Press", was also applied to investigate the warpage of two different grades of LLDPE under typical rotational molding conditions, which means slow cooling from only one side. The crystallinity and spherulitic morphology along the thickness of the rotationally molded parts were studied by Differential Scanning Calorimetry and Polarized Light Optical Microscopy. It is shown that the warpage increases with increasing cooling rate. The increase in diameter of the venting tube is more effective in reducing the warpage of rotationally molded parts, especially for lower cooling rates. In hot press experiments the grade of LLDPE with lower melt flow index and higher flexural strength presented lower warpage. The part thickness affects the warpage in hot press experiments only for faster cooling rates. In general, crystallinity and spherulitic diameter are lower in positions along the cross section of the rotationally molded part where the cooling rate is faster.

Keywords: Rotomoulding, warping, linear low density polyethylene.

\section{Introdução}

Rotomoldagem é um processo de manufatura de materiais poliméricos usado para produzir peças ocas ou abertas. O processo de rotomoldagem é encontrado em diversos setores da indústria, destacando-se na indústria automotiva, de reservatórios, de brinquedos e lazer, esportes entre outras. A rotomoldagem teve seu início na indústria na década de 50 e tem mostrado um grande crescimento nos últimos anos ${ }^{[1,2]}$.

A rotomoldagem é um processo altamente dependente da matéria prima e não poderia existir sem materiais poliméricos adequados ao processo. Para ser rotomoldado, um polímero tem que ter resistência térmica e química para não sofrer degradação termo oxidativa devido a longos períodos de permanência no forno, além de ter valores de viscosidade aceitáveis para o processamento. $\mathrm{O}$ material mais utilizado no processo é o polietileno $(\mathrm{PE})$, e nesta classe se destaca o Polietileno Linear de Baixa Densidade (PELDB). Outros materiais aplicados no processo com relativo sucesso são o polipropileno (PP), poliamida (PA), policloreto de vinila (PVC) e o policarbonato (PC) ${ }^{[2-6]}$.

$\mathrm{O}$ processo de rotomoldagem produz peças praticamente livres de tensões residuais, sem linhas de solda e com custo de ferramental relativamente mais baixo quando comparados a outras técnicas de processamento usuais. Estas vantagens têm alavancado o crescimento do setor na indústria. Atualmente é o processo de transformação de materiais poliméricos que tem o maior crescimento anual ${ }^{[2,4,7]}$.

Devido a este potencial de crescimento, o processo vem atraindo o interesse de empresas e grupos de pesquisa no sentido de aperfeiçoar e compreender melhor o processo. Estes estudos estão direcionados em reduzir o tempo de ciclo, na sinterização do material, no design de moldes e equipamentos, na utilização de novos materiais e na qualidade do produto moldado. Estudos recentes comprovaram que a variável mais importante para 
controle do processo é a temperatura do ar dentro do molde, que revela as etapas chaves da moldagem rotacional ${ }^{[1,2,4]}$.

Existem muitos trabalhos na literatura para desenvolver técnicas de redução do tempo de resfriamento no processo de rotomoldagem utilizando moldes com diferentes materiais, superfícies aletadas e estudos de simulação para previsão do ciclo de moldagem. Estes trabalhos vêm revelando que o aumento da transferência de calor do molde aumenta o nível de empenamento das peças moldadas ${ }^{[2,8-13]}$.

$\mathrm{Na}$ rotomoldagem o resfriamento é assimétrico e produz um gradiente térmico através da espessura da peça que induz tensões residuais levando a formação de um momento fletor que provoca a distorção de sua geometria, levando ao empenamento. Quanto maior a taxa de resfriamento utilizada maior será o gradiente de temperatura, maior o nível de tensão residual através da espessura da peça e, consequentemente, ocorrerá um aumento na magnitude do momento fletor ${ }^{[14,15]}$.

A tensão desenvolvida no processo de rotomoldagem inicia com a solidificação do polímero em contato com a parede do molde. Pode-se visualizar o polímero como um fluido que se solidifica camada a camada em um resfriamento livre. A primeira camada a se solidificar próxima a superfície interna do molde se deforma sob uma tensão de tração insignificante. Cada camada subsequente se solidifica e se une com o material já solidificado submetendo-se a uma contração de volume. A solidificação das camadas subsequentes ocorre sob restrição das camadas anteriores já solidificadas, aumentando o nível de tensão residual compressiva nestas camadas. Considerando a retração térmica e o resfriamento assimétrico, as deformações surgidas são maiores quanto mais perto da superfície interna do molde. Assim, o material próximo à superfície do molde fica sob tensões compressivas enquanto que o material próximo à superfície livre está sob tensões de tração ${ }^{[14,15]}$.

Em trabalho experimental Liu e $\mathrm{Ho}^{[16]}$ relataram que o empenamento de peças rotomoldadas também está relacionado com o perfil de pressão do ar dentro do molde. Antes do resfriamento o molde está aquecido e, consequentemente, o ar no seu interior também. Assim, ocorre um aumento de pressão do ar interno no aquecimento, fazendo com que parte deste deixe o molde através do tubo de ventilação. Quando o molde é resfriado o ar interno se contrai, diminuindo sua pressão e fazendo com que ocorra uma transferência de massa do ar do ambiente externo para o interior do molde. Entretanto, quando o resfriamento é muito rápido ou o tubo de ventilação não apresenta diâmetro grande o suficiente, a equalização de pressão no resfriamento não ocorre de forma rápida o suficiente, induzindo assim uma queda de pressão dentro do molde. Essa variação de pressão puxa o polímero parcialmente fundido causando o empenamento da peça.

No processo de rotomoldagem, o empenamento é também influenciado por uma série de outros fatores. Estudos experimentais recentes mostraram que o empenamento está relacionado com a taxa de resfriamento, cristalinidade e efeito do agente desmoldante ${ }^{[17]}$. Pop-lliev et al. ${ }^{[18]}$ concluíram que o empenamento aumenta com o aumento da espessura da peça. Entretanto, Liu e $\mathrm{Ho}^{[8]}$ concluíram o oposto sobre o efeito da espessura. De acordo com Glosamker et al. ${ }^{[17]} \mathrm{o}$ aumento da espessura da peça aumenta o empenamento, mas quando não há adesão entre a peça e as paredes do molde o efeito pode ser oposto.

Glosamker et al. ${ }^{[17,19]}$ propuseram uma técnica, denominada "Hot press", independente da geometria do molde para avaliar o empenamento para diversos polímeros através de medidas de raio de curvatura em peças resfriadas assimetricamente. Neste aspecto, este equipamento possui características comuns ao processo de rotomoldagem, e consiste em uma caixa isolante recobrindo uma chapa metálica (substrato) com temperatura controlada. A caixa isolante torna a transferência de calor no experimento unidimensional, pois se dá apenas através da chapa metálica.

Neste trabalho, Glomsaker et al. ${ }^{[19]}$ investigaram o empenamento de peças resfriadas assimetricamente considerando a condição de adesão entre a peça e o substrato e a variação da espessura. A partir de dados experimentais e a utilização de um modelo teórico eles determinaram que para haver o empenamento as tensões desenvolvidas na peça têm que superar a força de adesão entre o polímero e o substrato metálico.

Os dados experimentais obtidos por experimentos de "Hot press" revelam que o aumento da espessura da peça aumenta o nível de empenamento. Este fenômeno sofre uma inversão para espessuras maiores que $3 \mathrm{~mm}$ onde o nível de empenamento diminui com o aumento da espessura da peça ${ }^{[19]}$

Mesmo em termos de literatura mundial ainda existem poucos trabalhos focados no empenamento na rotomoldagem. No Brasil os estudos deste processo são extremamente escassos, e praticamente não existem trabalhos publicados sobre o empenamento na rotomoldagem. Portanto, o objetivo do presente trabalho é correlacionar as condições de processamento com o nível de empenamento das peças rotomoldadas, considerando variáveis como taxa de resfriamento, diâmetro de tubo de saída de ar (respiro do molde) e espessura da peça.

\section{Material e Métodos}

\section{Material}

Neste trabalho foram utilizados dois tipos de Polietileno Linear de Baixa Densidade (PELBD), MR435UV e RA34U3, gentilmente fornecidos pela empresa BRASKEM S.A. A Tabela 1 mostra as propriedades destes polímeros segundo o fabricante.

Estes diferentes grades foram utilizados em experimentos de "Hot Press". Nos experimentos de empenamento na rotomoldagem foi utilizado somente o PELBD RA34U3 micronizado com granulometria \# 35 .

Tabela 1. Propriedades de diferentes PELBD, BRASKEM S.A ${ }^{[35]}$.

\begin{tabular}{|c|c|c|c|c|}
\hline Propriedades & Método ASTM & Unidade & PELBD MR435UV & PELBD RA34U3 \\
\hline Índice de fluidez & D 1238 & $\mathrm{~g} / 10 \mathrm{~min}$ & 4,0 & 4,2 \\
\hline Densidade & D 792 & g.cm ${ }^{-3}$ & 0,934 & 0,935 \\
\hline Temperatura de fusão & D 3418 & ${ }^{\circ} \mathrm{C}$ & 129 & 125 \\
\hline Temperatura deflexão térmica (0,45 MPa) & D 648 & ${ }^{\circ} \mathrm{C}$ & 60 & 56 \\
\hline Temperatura deflexão térmica (1,80 MPa) & D 648 & ${ }^{\circ} \mathrm{C}$ & 41 & 40 \\
\hline Tensão de escoamento & D 638 & Mpa & 21 & 17 \\
\hline Alongamento no escoamento & D 638 & Mpa & 15 & 17 \\
\hline Módulo de flexão & D 790 & Mpa & 720 & 530 \\
\hline Resistência ao impacto $\left(-40^{\circ} \mathrm{C}\right)$ & ARM & $\mathrm{J}$ & 35 & 49 \\
\hline
\end{tabular}




\section{Métodos}

\section{Empenamento de peças rotomoldadas}

Para a realização de experimentos de rotomoldagem foi confeccionado um molde metálico cúbico em aço com dimensões de $300 \times 300 \times 300 \mathrm{~mm}$ de acordo com trabalhos descritos na literatura ${ }^{[9,11,20,21]}$. Para estudar o efeito do perfil de pressão negativo desenvolvido dentro da peça durante o resfriamento foi utilizado um tubo de ventilação com $150 \mathrm{~mm}$ de comprimento, $18 \mathrm{~mm}$ de diâmetro externo e $4 \mathrm{~mm}$ de espessura de parede, que foi fixado na tampa do molde. Para este tubo foram utilizadas duas tampas com furo central de 2 e $5 \mathrm{~mm}$ para variar o diâmetro de saída de ar durante os experimentos.

Os experimentos de rotomoldagem foram realizados na empresa Rio \& MAR LTDA localizada na cidade de Dracena-SP, que gentilmente disponibilizou a máquina de rotomoldagem do tipo lançadeira, de fabricação própria. De acordo com a literatura ${ }^{[2,4]}$, foi utilizada uma proporção de rotação entre o braço e suporte do molde 4:1 com velocidade de rotação de 8 e 2 rpm, respectivamente. Para determinar o tempo ideal de forno, foram realizados testes medindo a temperatura do ar dentro do molde obtendo-se um valor de 14 minutos de permanência dentro do forno para que o ar interno atingisse a temperatura de $200{ }^{\circ} \mathrm{C}^{[4,10,11,22]}$.

Para análise do empenamento foram feitos experimentos utilizando resfriamento por convecção natural, convecção forçada e spray de água. Para variar o perfil de pressão dentro do molde foram utilizados dois tubos de saída de ar com diâmetros de 2 e $5 \mathrm{~mm}$. Também foram realizados experimentos com diferentes massas, 900, $1200 \mathrm{e} 1500 \mathrm{~g}$ de polímero para obter amostras com espessuras variadas.

$\mathrm{O}$ perfil de empenamento das peças moldadas foi medido utilizando um gabarito de madeira com furos e um paquímetro. $\mathrm{O}$ perfil de empenamento foi medido sempre na face oposta à face do tubo de resfriamento.

\section{Experimentos de "Hot Press"}

Para realização dos experimentos de Hot Press foram confeccionados corpos de prova com dimensões de $100 \times 10 \mathrm{~mm}$ com diferentes espessuras, 2, 3 e $4 \mathrm{~mm}$, através da técnica de moldagem por compressão. Para moldagem dos corpos de prova foi utilizado material na forma de pellets, prensados a quente a $180{ }^{\circ} \mathrm{C}$ e força de prensagem de 4 toneladas.

Nos experimentos de "Hot Press" foi projetada e confeccionada uma caixa isolante térmica, composta por madeira e feltro, para reproduzir a condição de resfriamento assimétrico do processo de rotomoldagem. No topo da caixa foi colocado um vidro para visualização das amostras durante o experimento. A parte inferior da caixa era composta por uma chapa de aço inox de $2 \mathrm{~mm}$ de espessura onde eram colocadas as amostras para realização dos experimentos de Hot Press ${ }^{[17,19]}$.

Para realização destes experimentos, a caixa com a amostra era colocada sobre uma placa aquecida a $165{ }^{\circ} \mathrm{C}$ onde permanecia por 8 minutos ou até que ocorresse a fusão total sem que o corpo de prova sofresse alteração em sua geometria. Depois deste aquecimento a caixa era retirada da placa aquecida e resfriada em condições de convecção natural ou com circulação de ar forçada, utilizando-se um ventilador.

Para avaliar o empenamento das amostras submetidas ao Hot Press, foi medida a distância entre a ponta do corpo de prova empenado e a superfície onde ele estava apoiado. Estes experimentos foram realizados de acordo com o descrito na literatura ${ }^{[17,19]}$.

\section{Microscopia óptica de luz polarizada (MOLP)}

Para aprofundar a análise das amostras rotomoldadas foram realizadas observações em microscopia óptica de luz polarizada para averiguar a influência de variáveis de processo na microestrutura do polímero ao longo da espessura da peça moldada.

Os corpos de prova foram extraídos da mesma face onde foram feitas as medidas de empenamento. Estas amostras foram cortadas em um Micrótomo de marca Leica RM2025 em espessuras de aproximadamente $60 \mu \mathrm{m}$ para que pudessem ser analisadas no microscópio com luz polarizada. A espessura do corte destas amostras e o ajuste do microscópio para obter as imagens foram feitos de acordo com literatura ${ }^{[23]}$. As micrografias foram feitas nas regiões ao longo da espessura próximas ao ar interno e nas regiões em contato com molde em amostras submetidas a diferentes condições de resfriamento.

\section{Calorimetria Exploratória Diferencial (DSC)}

Experimentos de DSC foram realizados para determinar o grau de cristalinidade em diferentes posições ao longo da espessura das amostras rotomoldadas. Os corpos de prova foram extraídos da face onde foram feitas medidas de empenamento das amostras rotomoldadas.

A partir destas amostras retirou-se uma camada de $1 \mathrm{~mm}$ de cada lado, sendo possível determinar o grau de cristalinidade na parte externa (E) em contato com a superfície do molde e na parte interna (I) onde o resfriamento é mais lento. A porcentagem de fase cristalina para cada amostra foi calculada a partir de dados de entalpia de fusão obtidos por DSC, $\Delta \mathrm{H}_{\text {fusão }}$, e entalpia de fusão do cristal perfeito, $\Delta \mathrm{H}^{\circ}{ }_{\text {fusão }}$, utilizando a Equação $3.1^{[24]}$. Os experimentos foram conduzidos em DSC 60 da Shimadzu a taxa de aquecimento de $10{ }^{\circ} \mathrm{C} / \mathrm{min}$ sob atmosfera de nitrogênio, tendo sido utilizadas massas de aproximadamente $5 \mathrm{mg}$.

$$
\% C=\frac{\Delta H_{\text {fusão }}}{\Delta H_{\text {fusão }}^{O}} \cdot 100
$$

\section{Resultados e Discussão}

\section{Empenamento de peças rotomoldadas}

O empenamento de peças rotomoldadas está diretamente relacionado à taxa de resfriamento, ao perfil de pressão desenvolvido dentro do molde durante o processo e ao momento de inércia da peça, que depende da resistência mecânica do polímero moldado e sua espessura. Estes fatores citados não afetam o empenamento de maneira isolada e sim como um todo ${ }^{[25,14-19]}$. A seguir será feita uma análise individual de cada fator, de modo a verificar a contribuição dos mesmos no empenamento das peças rotomoldadas de acordo com as diferentes condições de processamento.

\section{Efeito da espessura da peça}

A Figura 1 mostra o perfil de empenamento das peças moldadas com diferentes taxas de resfriamento e com diâmetro de tubo de saída de ar do molde de $2 \mathrm{~mm}$.

A Figura 1a mostra que para peças com resfriamento com convecção natural, o aumento na espessura diminui o nível de empenamento. Observa-se uma clara definição deste comportamento.

Para taxas de resfriamento mais elevadas, convecção forçada de ar, Figura 1b, observa-se o mesmo comportamento mostrado por peças resfriadas por convecção natural. Quanto maior a espessura da peça menor é o nível de empenamento. Uma comparação entre a Figura 1a, b mostra que os perfis de empenamento das amostras mais finas, com 900 e $1200 \mathrm{~g}$, respectivamente, apresentam níveis de empenamento muito semelhantes.

Com o aumento taxa de resfriamento, uso de spray de água, Figura 1c, observa-se uma inversão do efeito da espessura da peça 
no empenamento das peças moldadas. Amostras mais espessas apresentam níveis de empenamento ligeiramente superiores do que as peças de menor espessura.

Resultados experimentais relatados na literatura mostram que o aumento da espessura da peça moldada pode tanto aumentar quanto diminuir o nível de empenamento desenvolvido na peça dependendo das condições de processamento ${ }^{[8,16-19]}$.

Também é importante ressaltar na Figura 1c que os perfis de empenamento das peças moldadas com diferentes espessuras possuem valores muito próximos. Nestes casos o resfriamento foi feito por spray de água e assim, a alta taxa de resfriamento se mostra um fator crítico no empenamento, sobrepondo o efeito da espessura (massa) da peça no perfil de empenamento.

As amostras moldadas com tubo de saída de ar com diâmetro de $5 \mathrm{~mm}$ apresentaram resultados similares às amostras moldadas com tubos de saída de ar com diâmetro de $2 \mathrm{~mm}$. A única diferença foi que o nível de empenamento das peças foi menor.

Através da Figura 1 é possível observar que o aumento da espessura da peça diminui o nível de empenamento. Este comportamento é esperado, pois o aumento da espessura aumenta

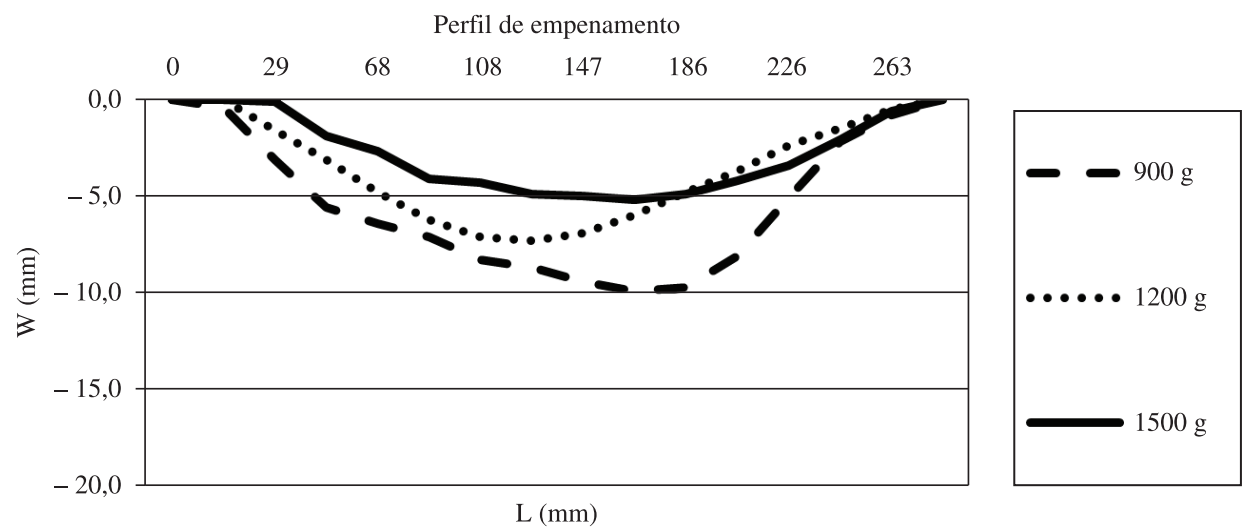

(a)

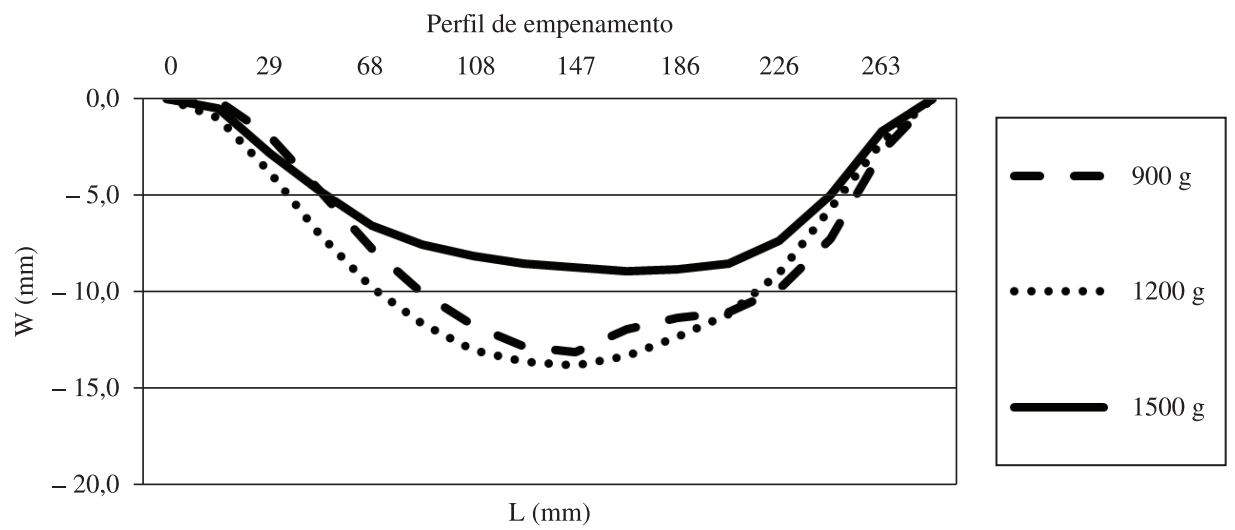

(b)

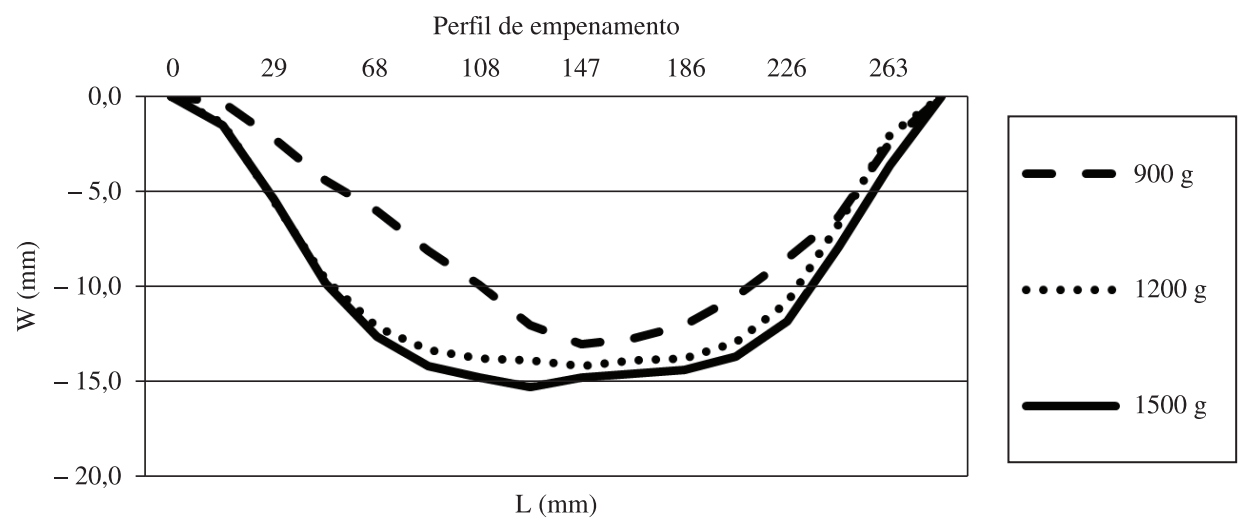

(c)

Figura 1. Perfil de empenamento de peças moldadas com diferentes espessuras. Condições de processo: tubo de saída de ar com diâmetro de 2 mm e resfriamento com a) convecção natural, b) convecção forçada e c) spray de água. 
o momento de inércia da peça, o que a torna mais resistente ao empenamento. Este efeito não foi observado claramente nos experimentos onde o resfriamento foi feito com uso de spray de água. Neste caso, para taxas de resfriamento elevadas, o efeito do aumento do momento de inércia é superado pelos elevados níveis de gradiente de tensão desenvolvidos na peça devido ao maior gradiente térmico através da espessura ${ }^{[14,15,19]}$.

\section{Efeito da taxa de resfriamento no empenamento de peças rotomoldadas}

A Figura 2 mostra o comportamento de peças moldadas com diferentes taxas de resfriamento e diferentes espessuras, com diâmetro do tubo de saída de ar de $2 \mathrm{~mm}$.

A Figura 2a, b mostra que o aumento da taxa de resfriamento aumenta o nível do empenamento das peças moldadas. Entretanto, as amostras submetidas à resfriamento forçado (convecção por

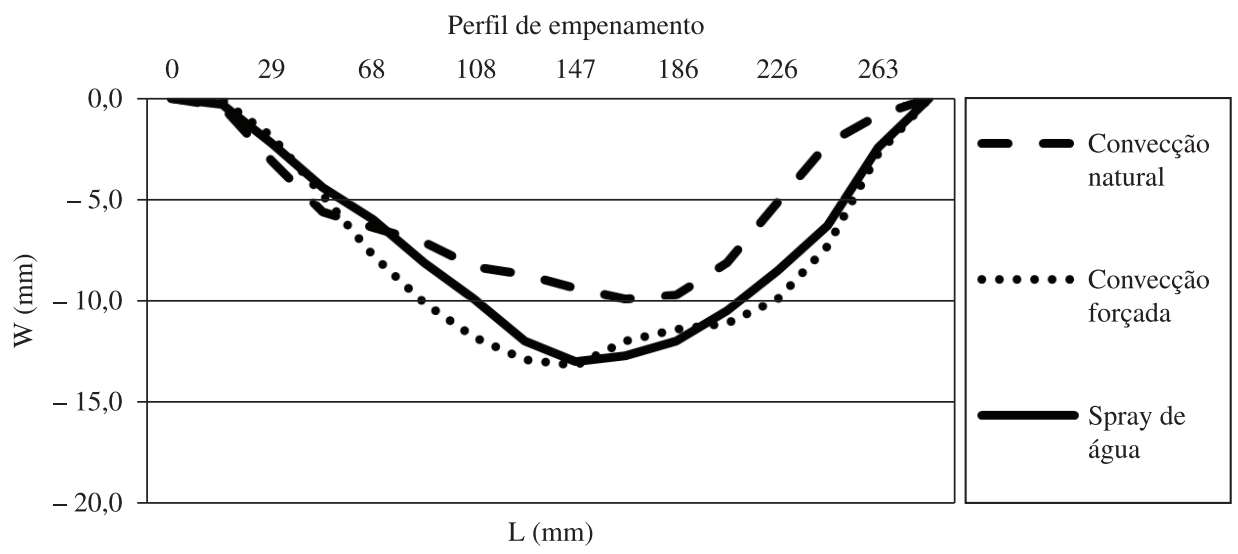

(a)

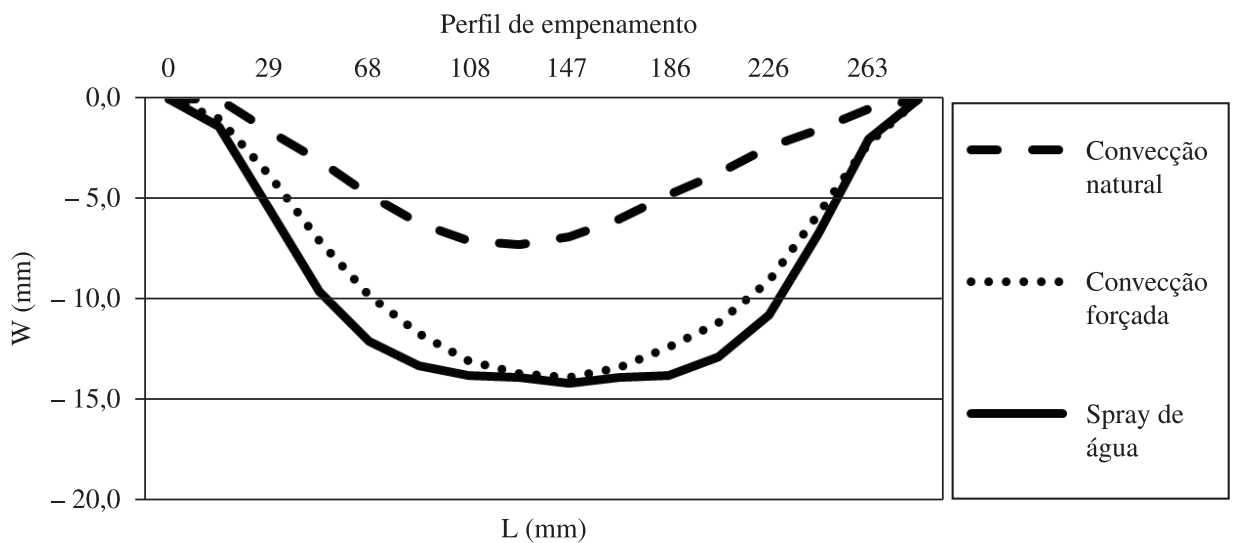

(b)

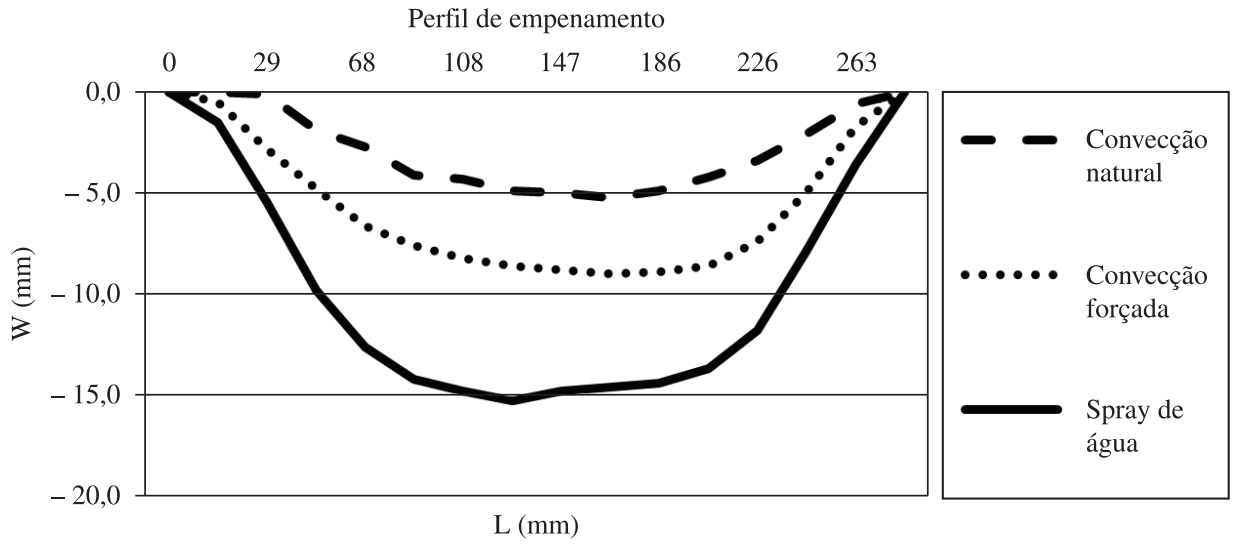

(c)

Figura 2. Efeito da taxa de resfriamento de peças moldadas com diâmetro de tubo de saída de ar do molde de $2 \mathrm{~mm}$ e com a) $900 \mathrm{~g}$, b) $1200 \mathrm{~g}$ e c) $1500 \mathrm{~g}$, de PELBD. 
ar forçado ou spray de água) apresentam níveis de empenamento parecidos, isto porque peças de menor espessura, 900 e $1200 \mathrm{~g}$ possuem uma menor resistência ao empenamento. Assim, para peças de menor espessura as taxas de resfriamento mais elevadas afetam significativamente o nível de empenamento.

Para peças de maior espessura, Figura 2c, o aumento da taxa de resfriamento também aumenta o nível de empenamento da peça moldada. Diferentemente dos resultados mostrados na Figura 2a, b, o nível de empenamento das peças moldadas aumenta gradativamente com a taxa de resfriamento. Peças com maior espessura possuem uma maior resistência ao empenamento e são menos susceptíveis ao empenamento do que peças de menor espessura. Assim, o nível de empenamento destas peças aumenta gradativamente com a taxa de resfriamento.

Os perfis de empenamento das peças moldadas com diferentes taxas de resfriamento e com diâmetro de tubo de saída de ar de $5 \mathrm{~mm}$ apresentaram o mesmo comportamento das peças moldadas com tubo de saída de ar com diâmetro de $2 \mathrm{~mm}$, mas com menor intensidade.

\section{Efeito do diâmetro do tubo de saída de ar no empenamento de peças rotomoldadas}

A Figura 3 mostra o perfil de empenamento desenvolvido em peças moldadas com diferentes espessuras, taxas de resfriamento e diâmetros de tubo de saída de ar. Através dos gráficos de perfil de empenamento na Figura 3 é possível observar que para resfriamentos com convecção de ar natural e forçado, o aumento do diâmetro do tubo de saída de ar diminui o nível de empenamento das peças rotomoldadas independentemente da espessura da peça.

A diferença entre o empenamento das peças com diferentes diâmetros de tubo de saída de ar é menos pronunciada nas peças submetidas ao resfriamento com convecção de ar natural do que nas peças resfriadas por convecção forçada. Para taxas de resfriamento muito lentas há tempo suficiente para equilibrar o perfil de pressão dentro da peça. Assim, este nível de pressão é pequeno e não se observa uma grande diferença no nível de empenamento das peças moldadas com diferentes diâmetros de tubos de saída de ar.

Este efeito do diâmetro do tubo de saída de ar não é observado nas amostras onde o resfriamento é feito com uso de spray de água. Estas peças moldadas com diferentes diâmetros de tubo de saída de ar do molde apresentaram níveis de empenamento relativamente altos. Para taxas de resfriamento mais bruscas o gradiente de tensão desenvolvido através da espessura da peça deve atingir um nível crítico que supera o efeito do tamanho do tubo de saída de ar no empenamento das peças rotomoldadas.

Nas amostras com resfriamento intermediário, convecção de ar forçada, observam-se diferenças expressivas nos níveis de empenamento para amostras moldadas com diferentes tubos de saída de ar, pois o efeito do gradiente de temperatura ainda não é tão expressivo para superar o efeito da pressão negativa. Assim, o resfriamento é rápido o suficiente para que existam níveis de pressão negativos significativos entre as amostras moldadas com diferentes diâmetros de tubos de saída de ar.

\section{Empenamento de amostras submetidas ao experimento de "Hot Press"}

A Figura 4 apresenta o comportamento das amostras de PELBD do tipo MR435UV e RA34U3 submetidas a experimentos de Hot Press com diferentes espessuras e taxas de resfriamentos. A partir da Figura 4, nota-se que as amostras submetidas ao resfriamento por convecção de ar natural apresentam valores de empenamento relativamente baixos e que o aumento da espessura da amostra não tem influência significativa no nível de empenamento nos experimentos de "Hot Press". Já para as amostras submetidas ao resfriamento por convecção de ar forçado o aumento da espessura da peça aumenta consideravelmente o nível de empenamento da amostra.

Observa-se que as amostras de PELBD do tipo RA34U3 apresentaram níveis de empenamento maiores do que as MR435UV. Como discutido anteriormente, quanto maior a rigidez da peça, maior será sua resistência ao empenamento ${ }^{[17,19]}$. De acordo com informações técnicas do fabricante, o PELBD do tipo MR435UV é mais rígido do que o PELBD do tipo RA34U3. Desta maneira, as amostras do polímero mais rígido apresentaram níveis de empenamento inferiores às amostras do polímero de menor rigidez.

\section{Microscopia ótica de peças rotomoldadas}

As Figuras 5 e 6 mostram a microestrutura de peças rotomoldadas com 1500 g de PELBD e diâmetro de tubo de saída de ar de $2 \mathrm{~mm}$. Nestas peças foram avaliadas a influência da taxa de resfriamento e a posição ao longo da espessura da peça na microestrutura.

Observam-se para baixas taxas de resfriamento, convecção de ar natural, Figura 5, que as microestruturas das amostras são diferentes de acordo com a posição da peça. Na superfície em contato com o molde observam-se pequenos esferulitos e nas regiões próximas ao ar interno os esferulitos são maiores. Nota-se a presença de esferulitos tipo cruz de malta e anelares que se apresentam na microestrutura na forma de padrões de extinção circular. O surgimento de esferulitos anelares está relacionado à estrutura do polímero, distribuição de massa molar, distribuição de ramificações ao longo da cadeia e tensões desenvolvidas na peça durante o processamento ${ }^{[26-29]}$.

Este tipo de microestrutura era esperado já que quanto mais próximo da parede de molde maior a taxa de transferência de calor, e para regiões mais afastadas se têm menores taxas de transferência de calor do polímero para o ambiente externo. O polímero é um mau condutor de calor e por isso ocorre este gradiente térmico durante a etapa de resfriamento do processo de rotomoldagem ${ }^{[14-19,25]}$. A microestrutura do polímero é altamente dependente da taxa de resfriamento, assim nas regiões próximas às paredes do molde, Figura 5a, as altas taxas de resfriamento levam à microestrutura que se apresenta como esferulitos pequenos quando comparados às regiões de menor taxa de resfriamento, Figura $5 b$, que apresentam esferulitos comparativamente maiores. $\mathrm{O}$ desenvolvimento da microestrutura é um processo cinético dependente do tempo de resfriamento e das condições de processo. Para taxas de resfriamento mais elevadas a cristalização se dá em menores temperaturas, com maior taxa de nucleação, formando estruturas esferulíticas menores.

Para as amostras resfriadas por convecção de ar forçado, houve certa dificuldade de obtenção de micrografias com qualidade gráfica adequada para inclusão no presente trabalho. Entretanto, permitiram observar que o desenvolvimento da microestrutura apresenta um comportamento semelhante às amostras resfriadas por convecção natural: esferulitos menores são observados nas regiões próximas às paredes do molde, de maior taxa de resfriamento, e esferulitos maiores nas regiões mais afastadas da parede do molde onde a taxa de resfriamento diminui consideravelmente. Nestas amostras também foi observada uma grande quantidade de esferulitos anelares.

Nas micrografias das amostras submetidas a resfriamento com spray de água, Figura 6, observam-se esferulitos muito pequenos nas regiões próximas às paredes do molde. Ao contrário dos casos anteriores, mesmo nas regiões mais internas, nota-se que o tamanho dos esferulitos é relativamente pequeno, quase que similar ao observado nas regiões em contato com as paredes do molde. Esta pequena diferença de tamanho dos esferulitos entre estas regiões pode ser explicada pelo fato destas amostras terem sido submetidas 
a elevadas taxas de resfriamentos. Portanto, mesmo na superfície interna as taxas de resfriamento são altas o suficiente para promover uma significativa densidade de nucleação em função de baixas temperaturas de cristalização.

As micrografias da Figura 6 também são compostas por esferulitos anelares e do tipo cruz de malta. Nota-se que estas imagens não apresentam uma boa definição, devido ao fato destas amostras apresentarem esferulitos muito pequenos que dificultam ajuste de foco no microscópio.
Observa-se que o tamanho dos esferulitos das amostras submetidas a diferentes condições de resfriamento nas regiões próximas a parede do molde são parecidos, Figuras 5a e 6a. Apesar do uso de meios de resfriamento diferentes, nestas regiões a transferência de calor é relativamente rápida devido à elevada condutividade térmica do molde metálico. Desta maneira, estas amostras apresentam microestrutura parecida nas regiões próximas do molde.

Nas regiões mais afastadas das paredes do molde, em contato com o ar interno, Figuras $5 \mathrm{~b}$ e $6 \mathrm{~b}$, onde as taxas de resfriamento

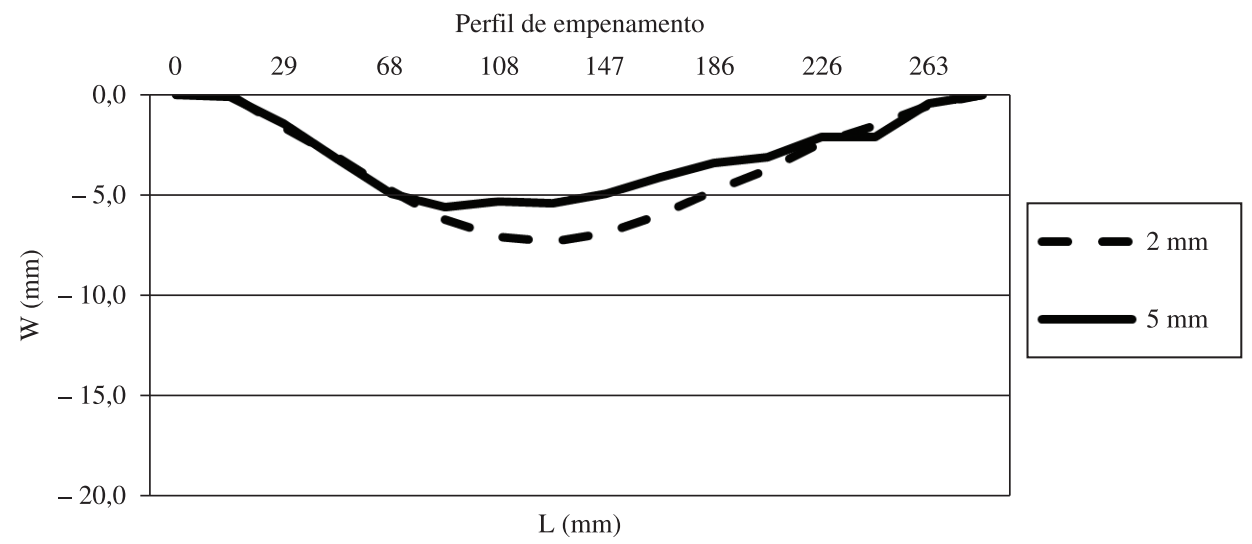

(a)

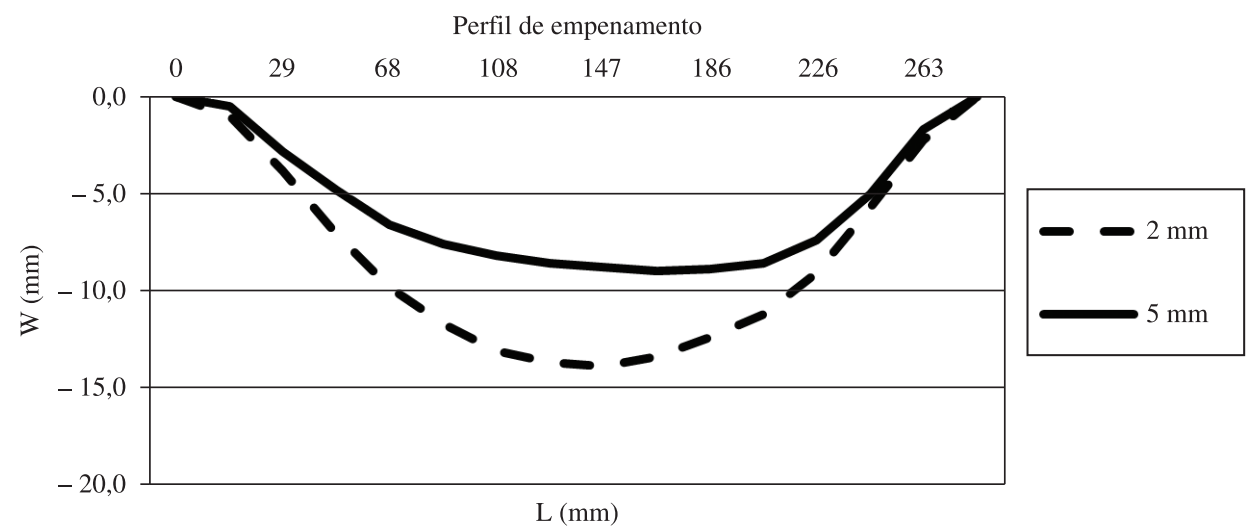

(b)

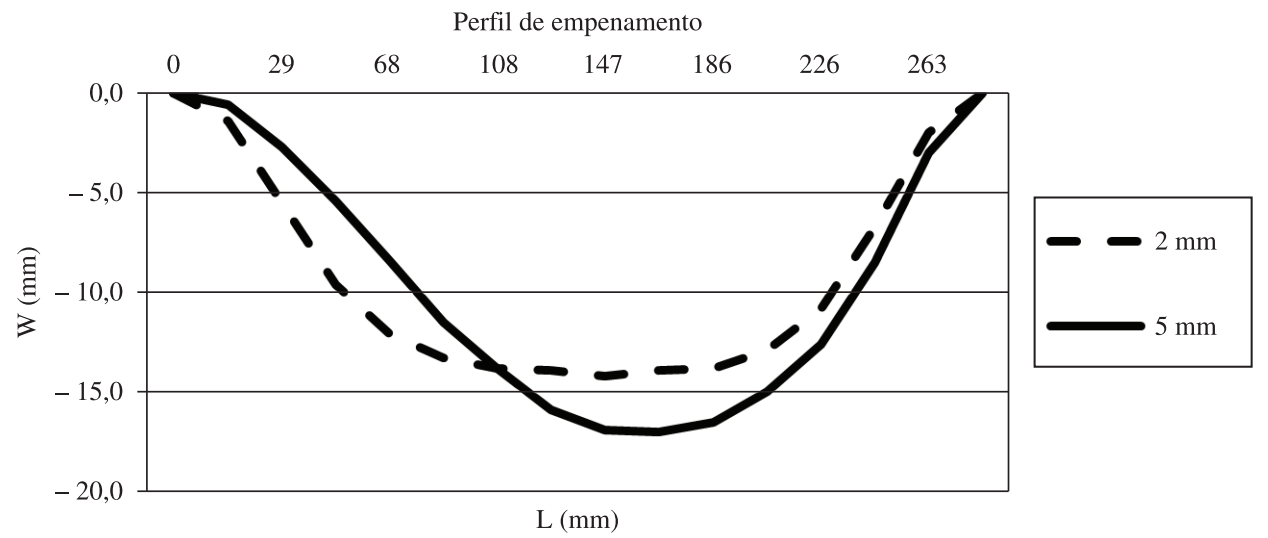

(c)

Figura 3. Perfil de empenamento de peças moldadas com $1200 \mathrm{~g}$ e diâmetros de tubo de saída de ar de 2 e 5 mm. Resfriamento com a) convecção de ar natural, b) convecção de ar forçada e c) spray de água. 
são menos pronunciadas, observam-se esferulitos com tamanhos bem diferentes. As amostras submetidas a resfriamentos mais lentos apresentam esferulitos grandes e em menor quantidade. $\mathrm{O}$ aumento da taxa de resfriamento diminui o tamanho dos esferulitos, que aparecem então em maior quantidade.

O aumento da taxa de resfriamento diminui o tempo disponível para as moléculas se organizarem durante o processo de cristalização e aumenta a densidade de nucleação dos esferulitos, resultando em uma grande quantidade de esferulitos de tamanho pequeno. Por outro lado, taxas de resfriamento mais brandas promovem uma menor densidade de nucleação resultando em uma microestrutura com esferulitos maiores e lamelas mais espessas ${ }^{[30,31]}$.

Observam-se através das Figuras 5 e 6 a presença de algumas bolhas nas amostras rotomoldadas em diferentes condições de processamento. O polímero em pó durante o aquecimento na rotomoldagem sofre um processo de coalescência e sinterização. Assim, é comum a presença de uma pequena quantidade de bolhas nas peças moldadas ${ }^{[1,4]}$. As bolhas encontradas na microestrutura das peças moldadas deste trabalho aparecem em pequenas quantidades e em pequenos tamanhos e podem ser consideradas inerentes ao processo. Para eliminar totalmente as bolhas dos artigos rotomoldados seriam necessários longos tempos de ciclo de aquecimento que provocariam a degradação do polímero diminuindo drasticamente suas propriedades mecânicas ${ }^{[32-34]}$.

A degradação termo oxidativa do PELBD promove a cisão da cadeia principal e gera a reticulação ente as cadeias principais. Como resultado, o desenvolvimento das microestruturas sob degradação apresenta esferulitos muito pequenos e com contornos altamente imperfeitos nas regiões próximas ao ar interno ${ }^{[30]}$. Nas micrografias próximas ao ar interno não foram observados esferulitos com características de degradação termo oxidativa.

\section{Calorimetria Exploratória Diferencial (DSC)}

\section{Cristalinidade ao longo da espessura de peças rotomoldadas}

Através de experimentos de DSC foi calculada a quantidade de fase cristalina (\%C) em diferentes posições ao longo da espessura, e em diferentes condições de processamento das amostras rotomoldadas. A Tabela 2 mostra os resultados de $\% \mathrm{C}$ das diferentes amostras.

Através dos dados da Tabela 2 observa-se que as regiões das amostras em contato com o molde, sujeitas a maiores taxas de resfriamento, apresentam menor quantidade de fase cristalina do que as regiões em contato com o ar interno, de menor taxa

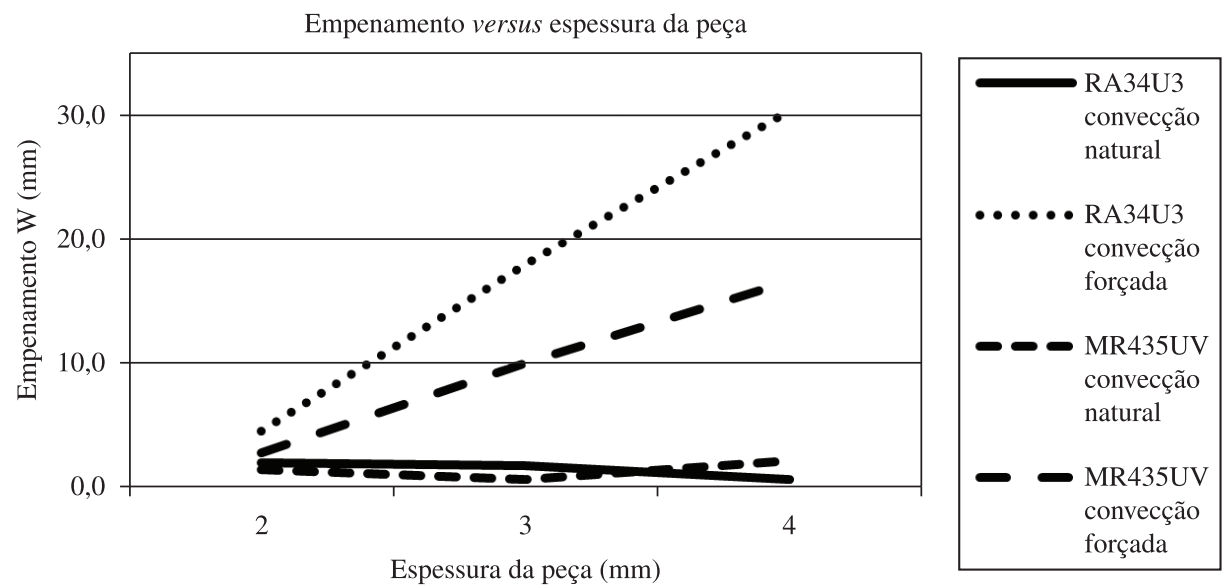

Figura 4. Amostras de PELBD do tipo MR435UV e RA34U3 submetidos a diferentes taxas de resfriamento e com diferentes espessuras.

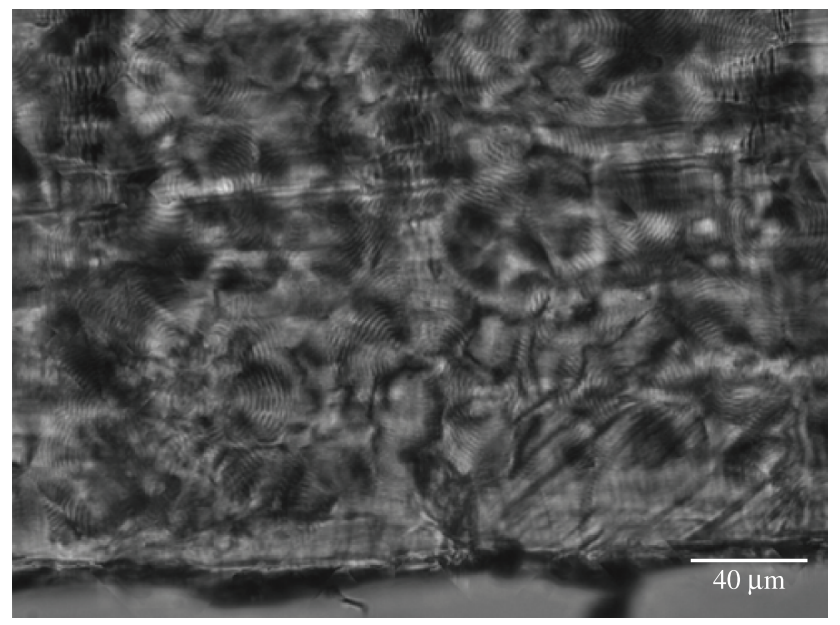

(a)

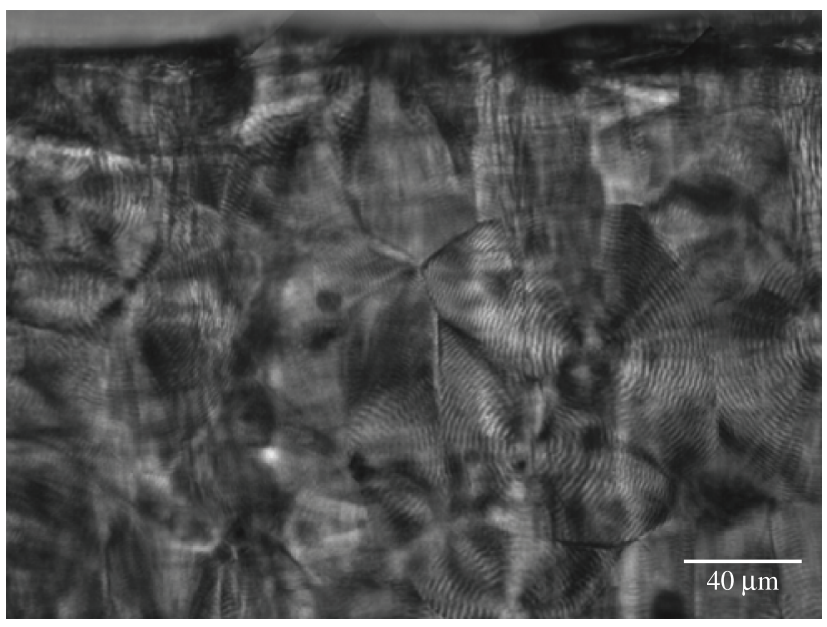

(b)

Figura 5. Microestrutura da peça rotomoldada com $1500 \mathrm{~g}$ de PELBD resfriada por convecção natural de ar: região em contato a) com o molde e b) com o ar dentro do molde. 
de resfriamento. Este comportamento é observado em todas as condições de resfriamento. Nas regiões em contato com o molde as taxas de resfriamento são mais elevadas. Assim o desenvolvimento da fase cristalina é menor, com maior densidade de nucleação onde são formados esferulitos menores, com lamelas mais finas e imperfeitas. Nas regiões em contato com ar interno as taxas de resfriamento são mais brandas e ocorre um maior desenvolvimento da estrutura cristalina, com uma menor densidade de nucleação e maior desenvolvimento dos esferulitos, com lamelas mais espessas e perfeitas.

O desenvolvimento da fase cristalina está intimamente ligado à taxa de resfriamento. Dessa maneira, quanto maior a taxa de resfriamento menor será a formação da estrutura cristalina no polímero $^{[30,31]}$. Os resultados obtidos por DSC estão de acordo com as micrografias obtidas para estas amostras onde as regiões submetidas a taxas de resfriamento mais brandas apresentaram

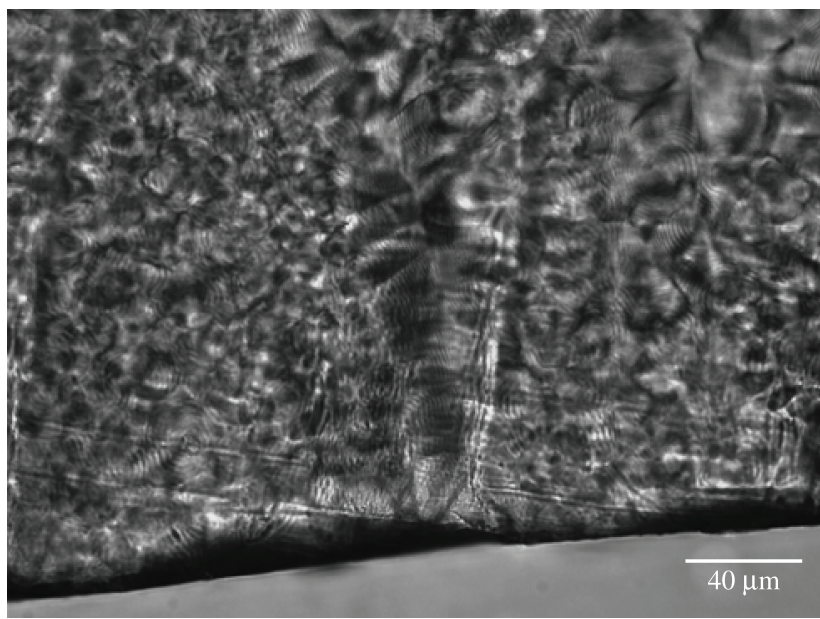

(a)

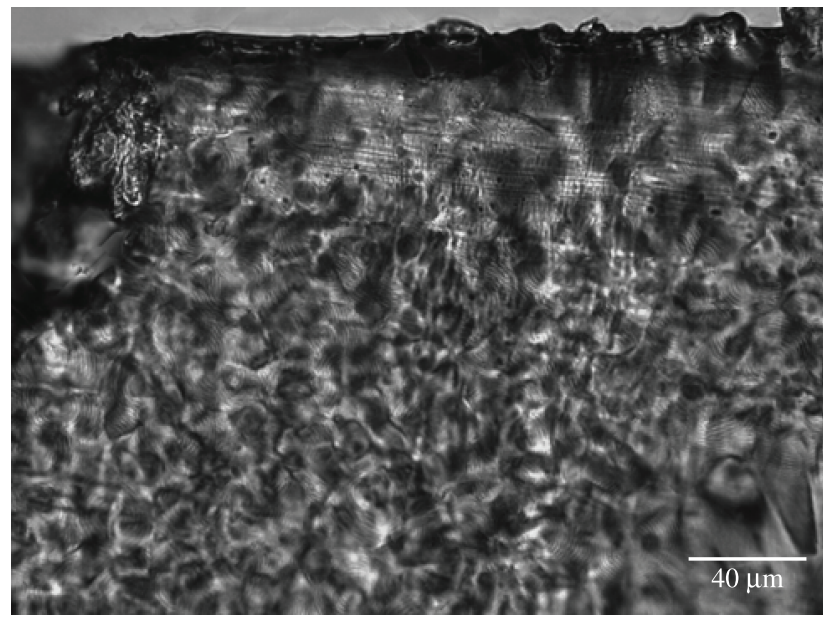

(b)

Figura 6. Microestrutura da peça rotomoldada com $1500 \mathrm{~g}$ de PELBD resfriada com spray de água: região em contato a) com o molde e b) com o ar dentro do molde.

Tabela 2. Quantidade de fase cristalina de diferentes amostras submetidas a diferentes condições de processamento.

\begin{tabular}{cllcc}
\hline Amostra & \multicolumn{1}{c}{ Resfriamento } & \multicolumn{1}{c}{ Posição amostra } & $\Delta \mathbf{H}_{\text {fuão }}\left(\mathbf{J} . \mathbf{g}^{-1}\right)$ & \% C \\
\hline CP03 & Convecção natural & Contato com molde & 120,7 & 46,4 \\
CP03 & Convecção natural & Contato com ar interno & 149,4 & 57,5 \\
CP06 & Convecção Forçada & Contato com molde & 124,3 & 47,8 \\
CP06 & Convecção Forçada & Contato com ar interno & 137 & 52,7 \\
CP09 & Spray de água & Contato com molde & 128,2 & 49,3 \\
CP09 & Spray de água & Contato com ar interno & 133,0 & 51,2 \\
\hline
\end{tabular}

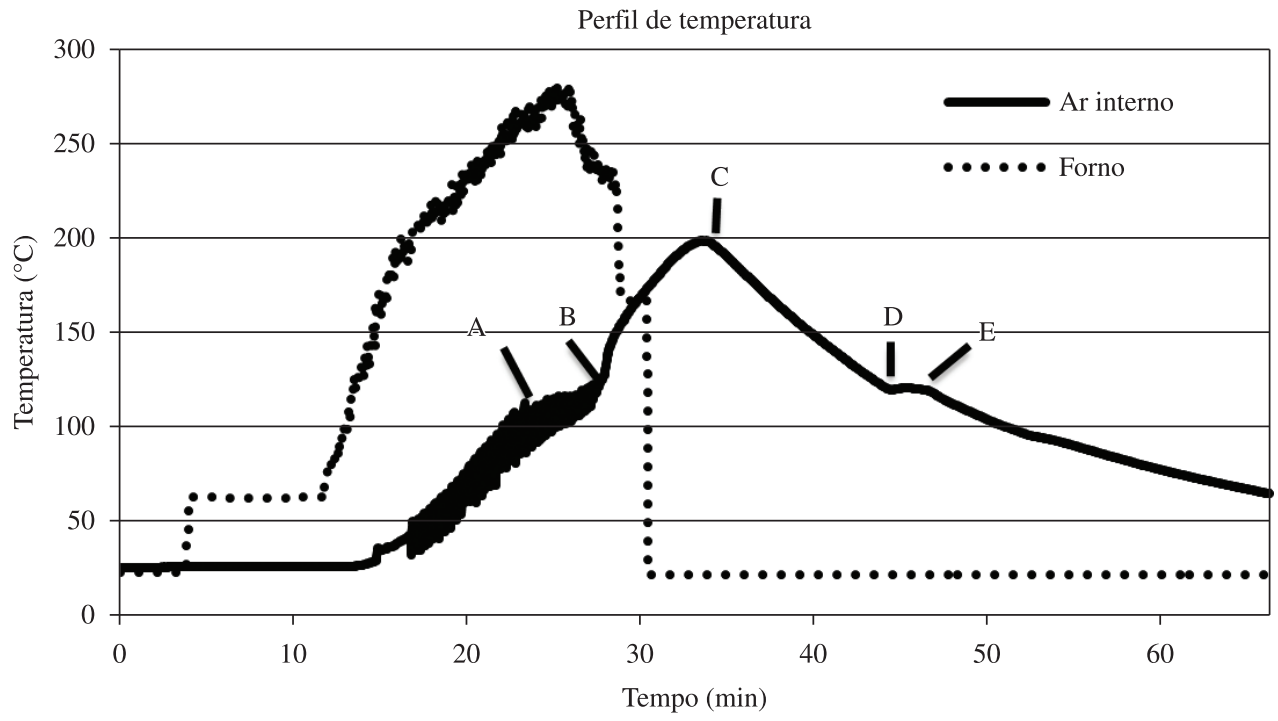

Figura 7. Perfil de temperatura típico do ar interno durante o processo de rotomoldagem. 
esferulitos maiores, com lamelas mais espessas e provavelmente mais perfeitas, apresentando maior grau de cristalinidade.

\section{Temperatura do ar interno em experimentos de rotomoldagem}

No presente estudo, foram realizados experimentos de medição do perfil de temperatura do ar interno (PIAT) durante o processo de rotomoldagem. Estudos recentes mostraram que o PIAT é a variável mais importante para controle do processo de rotomoldagem e revela estágios chaves do processo ${ }^{[2,4]}$.

A Figura 7 mostra o perfil de temperatura do ar interno de uma amostra rotomoldada no presente trabalho, assim como a temperatura do forno durante o processamento. No início da curva da temperatura do ar interno até o ponto A, a temperatura aumenta a uma taxa praticamente constante. Neste trecho o polímero ainda está sob a forma de pó. Do ponto A até o ponto B ocorre uma diminuição da taxa de aquecimento devido ao processo de fusão do polímero. A fusão é um processo endotérmico, ou seja, absorve calor fazendo com que a taxa de aquecimento diminua. A partir do ponto B a taxa de aquecimento aumenta novamente com o final do processo de fusão do polímero e atinge valores próximos aos exibidos no trecho até o ponto $\mathrm{A}$.

No ponto $\mathrm{C}$ a temperatura do ar interno atinge seu pico (PIAT). Por volta de $200{ }^{\circ} \mathrm{C}$ nota-se que o molde foi retirado do forno um pouco antes do PIAT atingir a sua máxima temperatura. Este fenômeno ocorre devido à inércia térmica, pois o fluxo de calor estava para dentro do molde se inverte quando ele é retirado do forno. Esta mudança não é instantânea, e por isso a temperatura do ar interno continua aumentando por mais algum tempo.

No trecho entre o ponto $\mathrm{C}$ e $\mathrm{D}$, o ar dentro do molde está sob regime de resfriamento a uma taxa praticamente constante, onde o polímero está na forma fundida. No ponto D ocorre uma diminuição na taxa de resfriamento, pois neste ponto ocorre o início do processo de cristalização que é um processo exotérmico. Assim a liberação de calor do polímero durante o processo de cristalização provoca uma diminuição na taxa de resfriamento. $\mathrm{O}$ processo de cristalização continua até o ponto $\mathrm{E}$ onde todo o polímero fundido se transforma em sólido. A partir do ponto E, o polímero sólido continua seu resfriamento até que atinja sua temperatura de desmoldagem ${ }^{[2,4,8-11]}$.

\section{Conclusões}

A taxa de resfriamento do polímero durante o processo de moldagem é um fator crítico no empenamento. O polímero possui coeficiente de condutividade térmica relativamente baixa. Assim o aumento da taxa de resfriamento aumenta o gradiente térmico através da espessura da peça e consequentemente aumenta o momento fletor desenvolvido na peça, resultando em um maior nível de empenamento do artigo moldado.

Durante a etapa de resfriamento na rotomoldagem ocorre o desenvolvimento de um perfil de pressão negativo do ar dentro do molde. Utilizar tubos de saída de ar no molde com diâmetro maior possibilita uma maior transferência da massa de ar dentro da peça para o ambiente externo, assim diminui o perfil de pressão desenvolvido e consequentemente diminui o nível de empenamento. $\mathrm{O}$ uso de diâmetros de tubo de saída de ar maior atenua o empenamento para taxas de resfriamentos mais brandas. Entretanto, para taxas mais elevadas o efeito do gradiente térmico prevalece sobre o efeito do diâmetro do tubo de saída de ar do molde.

O uso de polímeros de maior rigidez diminui o empenamento. O surgimento das distorções está relacionado ao desenvolvimento de um momento fletor na peça que provoca seu empenamento, desta maneira quanto maior a rigidez do polímero melhor será sua resistência ao momento fletor desenvolvido e menor será o nível de empenamento.

A microestrutura desenvolvida pelo polímero durante o processo de rotomoldagem está diretamente relacionada à taxa de resfriamento da peça. A parte externa em contato com molde apresenta esferulitos relativamente menores quando comparada com as regiões em contato com o ar dentro da peça. $\mathrm{O}$ gradiente térmico através da espessura da peça provoca o surgimento de regiões com diferentes tamanho de estruturas cristalinas e graus de cristalinidade que são afetados pela magnitude da taxa de resfriamento.

Nos experimentos de "Hot Press" o PELBD com menor índice de fluidez e maior módulo de flexão apresentou menor empenamento. Nestes experimentos a espessura das peças afetou o empenamento somente para taxas de resfriamento mais rápidas.

\section{Agradecimentos}

- À Empresa Rio \& MAR LTDA localizada na cidade de Dracena-SP, pela gentil disponibilização do equipamento de rotomoldagem;

- À Braskem S.A na pessoa do Engenheiro Leandro de Castro Tomasi pela gentil doação das resinas de PELBD; e

- À Fundação Araucária pela concessão da bolsa de mestrado ao aluno Tiago Boni Comisso.

\section{Referências Bibliográficas}

1. Crawford, R. J. - "Rotational moulding of plastics", John Willey, New York (1996).

2. Beall, G. L. - "Rotational Molding: Design, Materials, Tooling and Procesing", Carl Hanser Verlag, Munich (1998).

3. Rotational molding resins: poly processing Company. Technical Bulletin (1999).

4. Crawford, R. J. P. - Polym. Eng. Sci., 56, p.263 (1996).

5. Cramez, M. C.; Oliveira, M. J. \& Crawford, R. J. - Polym. Degrad. Stabil., 75, p.321 (2002). http://dx.doi.org/10.1016/S01413910(01)00234-8

6. Kontopoulou, M. \& Vlachopoulos, L. Polym. Eng. Sci., 41, p.165 (2001). http://dx.doi.org/10.1002/pen.10718

7. Torres, F. G. \& Aragon, C. L. - Polim. Test., 25, p.568 (2006). http:// dx.doi.org/10.1016/j.polymertesting.2006.03.010

8. Liu, S.-J. \& Ho, C.-F. - Adv. Polym. Tech., 18, p.201 (1999). http:// dx.doi.org/10.1002/(SICI)1098-2329(199923)18:3<201::AIDADV1>3.0.CO;2-N

9. Abdullah, M. Z.; Bickerton, S. \& Bhattacharyya, D. - Polym. Eng. Sci., p.1406 (2007). http://dx.doi.org/10.1002/pen.20835

10. Crawford, R. J. - "Advances in the Rotational Moulding of Plastics", John Willey, New York (1999).

11. Abdullah, M. Z.; Bickerton, S. \& Bhattacharyya, D. - Polym. Eng. Sci., p.1420 (2007). http://dx.doi.org/10.1002/pen.20834

12. Koppen, C.; Carvalho B. M. \& Pariona M. - "Influência da camada de ar entre poliamida e molde na etapa de resfriamento da rotomoldagem", in: Anais do $9^{\circ}$ Congresso Brasileiro de Polímeros, (2008).

13. Galera, V. V. - "Simulação da etapa de resfriamento da poliamida 66 no processo de moldagem rotacional", Dissertação de Mestrado, Universidade Estadual de Ponta Grossa, Brasil (2007).

14. Xu, H. \& Bellehumeur, C. T. - Polym. Eng. Sci., 48, p.283 (2008). http://dx.doi.org/10.1002/pen.20887

15. Lim, K. K. \& Inakiev, A. - Polym. Eng. Sci., 46, p.960 (2006). http:// dx.doi.org/10.1002/pen.20481

16. Liu, S.-J. \& Ho, C.-F. - J. Reinf. Plast. Comp., 19, p.992 (2000). http:// dx.doi.org/10.1106/XMXH-C1PG-91R8-M1GX 
17. Glomsaker, T.; Hinrichsen, E. L.; Larsen, Å.; Doshev, P. \& Ommundsen, E. - Polym. Eng. Sci., 49, p.523 (2009). http://dx.doi.org/10.1002/ pen. 21322

18. Pop-Lliev, R. et al. - Polym. Proc. Soc., 17, p.18 (2002).

19. Glomsaker, T.; Larsen, Å.; Andreassen, E. \& Ommundsen, E. - Polym. Eng. Sci., p.945 (2005). http://dx.doi.org/10.1002/pen.20348

20. Abdullah, M. Z.; Bickerton, S. \& Bhattacharyya, D. - Polym. Eng. Sci., 45, p.114 (2005). http://dx.doi.org/10.1002/pen.20236

21. Abdullah, M. Z.; Bickerton, S. \& Bhattacharyya, D. - Polym. Eng. Sci., 47, p.1420 (2007). http://dx.doi.org/10.1002/pen.20834

22. Kontopoulou, M. \& Vlachopoulos, L. - Polym. Eng. Sci., 39, p.1989 (1999).

23. Sawyer, L. C.; Grubb, D. T. \& Meyers, G. F. - "Polymer Microscopy", Springer (2008).

24. Mark, J. E. - "Polymer Data Handbook", Oxford University Press (1999).

25. Bawiskar, S. \& White, J. L. - Polym. Eng. Sci., 34, p.815 (1994). http:// dx.doi.org/10.1002/pen.760341006

26. Keith, D. H. \& Padden, F. J. - Macromolecules, 29, p.7776 (1996). http://dx.doi.org/10.1021/ma960634j

27. Sazaki, S.; Sakaki, Y.; Takahara, A. \& Kajiyama, T. - Polymer, 43, p.3441 (2002). http://dx.doi.org/10.1016/S0032-3861(02)00158-1
28. Schuktz, J. M. - Polymer, 44, p.433 (2003). http://dx.doi.org/10.1016/ S0032-3861(02)00724-3

29. Woo, E. M.; Wu, P. L.; Wu, M. C. \& Yan, K. C. - Macromol. Chem. Physic., 207, p.2232 (2006). http://dx.doi.org/10.1002/ macp. 200600379

30. Pick, L. T.; Harkin-Jones, E.; Oliveira, M. J. \& Cramez, M. C. - Wiley Int. Sci., p.1963 (2005).

31. Chiu, F. C.; Fu, Q.; Peng, F. \& Shih, H. H. - J. Polym. Sci., 40, p.325 (2002).

32. Nam, J. Y.; Kadomatsu, S.; Saito, H. \& Inoue, T. - Polymer, 43, p.2101 (2002). http://dx.doi.org/10.1016/S0032-3861(01)00709-1

33. Wang, Y. \& Yan, W. - Chinese Sci. Bull., 52, p.736 (2007). http:// dx.doi.org/10.1007/s11434-007-0093-4

34. Feng, L. \& Kamal, M. R. - Polym. Eng. Sci., 45, p.1140 (2005). http:// dx.doi.org/10.1002/pen.20389

35. Braskem. - "Poliolefinas: Tabela de Propriedades". Disponível em: $<$ http://www.braskem.com.br/site/portal_braskem/pt/produtos_e_ servicos/boletins/pdf_catalogos/Poliolefinas\%20PORT.pdf>. Acesso em: 04 nov. 2010.

Enviado: 28/09/11

Reenviado: 12/03/12

Aceito: 13/03/12 